Treichler, R. \& Mitchell, H. H. (I94I). F. Nutrit. 22, 333.

Voit, C. (1869a). Z. Biol. 5, 329.

Voit, C. $(1869 b)$. Z. Biol. 5, 431 .

Weir, J. B. de V. (1949). F. Physiol. rog, I.

Wiley, F. H. \& Newburgh, L. H. (1931). J. clin. Inzest. ro, 733.

\title{
Variations in the Pigment and Vitamin A Contents of Egg Yolk
}

\author{
By F. H. GRIMBLEBY AND D. J. G. BLACK \\ University of Reading
}

(Received I Yune 1950)

The first real contribution to our knowledge of the composition of the yolk pigments was made by Thudichum ( 1869 ), who showed that the yellow pigment of egg yolk was fat-soluble and unsaponifiable. He demonstrated the similarity between this pigment, which he called 'luteine', and the pigments of butter, corpus luteum and plant materials. Later Schunck ( 1903 ) compared the absorption spectrum of yolk pigment with those of a number of other naturally occurring pigments, and showed that the pigment was identical with leaf xanthophyll but different from carotene. Willstatter \& Escher ( $\mathrm{I}$ I I I), using over a thousand eggs, prepared $4 \mathrm{~g}$. crystalline pigment and determined its formula, which they found identical with that of leaf xanthophyll, $\mathrm{C}_{40} \mathrm{H}_{58} \mathrm{O}_{2}$, but they could not decide that the two substances were identical and eventually concluded that they were isomers. These same workers isolated a small quantity of a second pigment, which they identified as carotene. More recently, experiments by Gillam \& Heilbron (1935) have shown that at least three pigments are present in normal yolks. The one present in greatest amount was xanthophyll, and the others were identified as cryptoxanthin and $\beta$-carotene. Researches by Kuhn, Winterstein \& Lederer (193I) have shown that the so-called xanthophyll is a mixture of lutein and zeaxanthin in the ratio of $7: 3$, so that at the present time the yolk pigments are regarded as a mixture of lutein and zeaxanthin, usually referred to as xanthophyll, with much smaller quantities of cryptoxanthin and $\beta$-carotene.

The exact physiological significance of some of the yolk pigments is still undecided. Capper, McKibbin \& Prentice (1931) found that vitamin A in the diets of chickens could be wholly replaced by $\beta$-carotene and that, as $\beta$-carotene was converted rapidly to vitamin $A$, it did not cause pigmentation of the beaks and shanks. Experiments by Palmer \& Kempster (1919) have indicated that fowls can be raised on a diet containing vitamin A but no xanthophyll, that absence of carotenoids from the diet from hatching to maturity has no effect on fecundity, and that the transference of carotenoid pigments to the yolk during laying is simply an excretory process replacing the process of accumulation and oxidation of the pigments in the skin of the fowl during a period of non-laying. Palmer \& Kennedy (1921), after giving a carotenoid-free diet to hens until colourless yolks were produced, found that subsequent pigment-free eggs produced healthy chicks, and Plimmer, Rosedale \& Raymond (1923) concluded from their own 
experiments that there was no relationship between the colour of egg yolk and hatchability. Kline, Schultze \& Hart (1932) have shown that xanthophyll exerts no vitamin A activity when fed to growing chicks, and also concluded that it was non-toxic.

On the other hand, experiments by Virgin \& Klussmann (1932) indicated that the hen may be able to utilize xanthophyll by converting it to either a provitamin $A$ or into some other growth-promoting factor. Further, Rydbom (1933) has found that, although rats cannot be maintained indefinitely on diets in which $\beta$-carotene has been replaced by xanthophyll, guinea-pigs continue to grow on such diets. von Euler \& Klussmann (1932), from a study of vitamin A storage in the livers of pigeons, concluded that both $\beta$-carotene and xanthophyll were capable of increasing the liver concentration of a substance having an absorption at $328-330 \mathrm{~m} \mu$.

The concentration of total pigment in egg yolk may therefore be of some significance, and it is further of importance to know how $\beta$-carotene, cryptoxanthin and xanthophyll are distributed in it. In view of the established relationship between the pigments, $\beta$-carotene and cryptoxanthin, and vitamin $\mathrm{A}$, a study of the yolk pigments cannot be considered complete without a simultaneous consideration of the vitamin A content of the yolk as well. So far no quantitative data on the distribution of the yolk pigments and the relation between yolk pigmentation and vitamin $A$ content for individual eggs have been reported, although some data have been recorded for bulk samples of yolk.

'This paper deals with experiments designed to give information on some of these important points.

\section{EXPERIMENTAL}

Birds. The experimental birds were Rhode Island Red hens selected at random from a flock of twenty-five breeding hens. They were given a grain mash from which maize and leafy materials were excluded, so that it was virtually free from carotenoid pigment. No vitamin A supplement was given, but the birds were allowed access to grass. They experienced no change in diet throughout the experimental period. Eggs from four of these birds, from the first egg laid in spring through the subsequent laying period, were examined for carotenoid pigments and vitamin $A$. The experiment was continued until the amounts of these constituents were maintained at an approximately constant level. In order to determine the extent to which the pigment and vitamin A levels in the first eggs laid were influenced by the length of the period of rest from production, the first eggs from a further eight birds, which had rested for varying lengths of time in the late winter, were examined for pigment and vitamin $\mathrm{A}$.

Figgs. Each egg was weighed and broken, and the yolk was scparated and weighed. The fatty fraction was extracted from the yolk by treatment with $15 \mathrm{ml}$. ethanol to precipitate the yolk protein and extraction of the mixture with three successive portions of a 50:50 mixture of diethyl ether and light petroleum. The combined extracts were evaporated at low temperature under reduced pressure to remove the solvents, and the residue of alcohol and fat was treated with $30 \mathrm{ml} .20 \%$ potassium hydroxide and heated under reflux until saponification was complete ( $3-5 \mathrm{~min}$.). After transferring the saponified fat to a separating funnel, $20 \mathrm{ml}$. diethyl ether were added, the mixture was shaken and allowed to stand, and the colourless lower layer containing alcohol and 
excess alkali was separated and discarded. The coloured upper layer was diluted with water and extracted four times with ether. The combined ether extracts were washed with water and dried over anhydrous sodium sulphate, and the unsaponifiable matter was then transferred to $50 \mathrm{ml}$. light petroleum. A portion of this solution was suitably diluted and the yellow colour then matched in a Lovibond tintometer. A further $20 \mathrm{ml}$. of the same solution was chromatographed on magnesium hydroxide; the three bands that formed separately were eluted, and the eluates were matched in the tintometer. A further portion of the light petroleum solution was evaporated and the residue dissolved in chloroform, and this solution was used to determine vitamin $A$ with the Carr-Price reagent, the blue colour being matched in the tintometer. 'The correction for the blue colour developed by carotenoids in the determination of vitamin A proved the same as that found by Moore (1930) and was applied throughout. 'The results of these determinations were finally expressed for pigment as $\mathrm{mg}$./ $\mathrm{egg}$ and for vitamin $\mathrm{A}$ as i.u./egg. Owing to slight inevitable losses of pigment during adsorption on magnesium hydroxide, the colour intensities of the eluates were not used directly to calculate the pigment contents. Instead, the colour intensity of the original light petroleum solution was apportioned between xanthophyll, cryptoxanthin and $\beta$-carotene in the ratio found by examination of the eluates after adsorption. This distribution of colour was calculated to weights of $\beta$-carotene, so that the quantities of total pigment quoted are the sum of the weights of $\beta$-carotene that would produce the same colour intensities as those actually found for the individual pigments.

\section{RESLLTS}

The results of these experiments are shown diagrammatically in Fig. I, and are summarized in Table $\mathrm{I}$. They indicate that the pigment and vitamin A contents of eggs were at a maximum at the beginning of lay in spring, and that they fell rapidly, as the laying

Table I. Pigment and ritamin A contents of egg yolks from four Rhode Island Red hens

\begin{tabular}{|c|c|c|c|c|c|c|c|}
\hline \multirow[b]{2}{*}{ Hen no. } & \multirow{2}{*}{$\begin{array}{c}\text { No. of } \\
\text { determi- } \\
\text { nations }\end{array}$} & \multicolumn{3}{|c|}{$\begin{array}{l}\text { Pigment } \\
\text { (mg./yolk) }\end{array}$} & \multicolumn{3}{|c|}{$\begin{array}{l}\text { Vitamin A } \\
\text { (i.u./yolk) }\end{array}$} \\
\hline & & Maximum & Minimum & Average & Maximum & Minimum & Average \\
\hline 43 & 43 & $1 \cdot 21$ & $0 \cdot 37$ & 0.70 & 292 & 104 & 177 \\
\hline 107 & 39 & $1 \cdot 22$ & 0.34 & 0.53 & 264 & 84 & 139 \\
\hline 46 & 40 & $1 \cdot 64$ & 0.13 & 0.70 & 292 & 104 & 173 \\
\hline 162 & 23 & 2.43 & 0.30 & $I \cdot 32$ & 388 & 128 & 278 \\
\hline
\end{tabular}

period progressed, to a comparatively low fluctuating level. This level was roughly maintained for the 6-week period during which examinations were made. The data supplied by hen no. 162 are of particular interest in that this bird stopped laying after five eggs had been laid in early March and rested from production for $\mathbf{2 6}$ days before again coming into lay. Pigment and vitamin A were again secreted in high concentrations in the first eggs of this second laying period and, after eight eggs had been laid, at progressively lower concentrations as laying proceeded.

It has been shown (cf. Cruickshank (1940) and Kon (1940)) that in bulked samples of egg yolk the pigment and vitamin A contents are related. Statistical treatment of the 
data obtained in this experiment gives a highly significant correlation between the pigment and vitamin A contents of individual eggs. The correlation coefficients calculated for these constituents in the eggs of the individual birds are listed in 'Table 2.

Table 2. Relation between contents of pigment ( $X$, expressed in mg./egg) and vitamin $A$ ( $Y$, expressed in i.u./egg) of individual eggs from four Rhode Island Red hens

$\begin{array}{rcclcc}\text { Hen no. } & \begin{array}{c}\text { No. of } \\ \text { netermi- } \\ \text { nations }\end{array} & \begin{array}{c}\text { Correlation } \\ \text { coefficient }\end{array} & \begin{array}{c}\text { Significance } \\ \text { Regression of }\end{array} & \begin{array}{c}\text { Regression of } \\ X \text { upon } Y\end{array} & \begin{array}{c}Y \text { upon } X \\ 43\end{array} \\ \mathbf{4 2} & 0.869 & \text { Highly significant } & X=0.00433 Y-0.066 & Y=174 X+55 \\ 107 & 39 & 0.624 & \text { Highly significant } & X=0.00315 Y+0.093 & Y=124 X+73 \\ 46 & 38 & 0.904 & \text { Highly significant } & X=0.00603 Y-0.282 & Y=136 X+70 \\ 162 & 21 & 0.923 & \text { Highly significant } & X=0.00678 Y-0.560 & Y=126 X+112\end{array}$
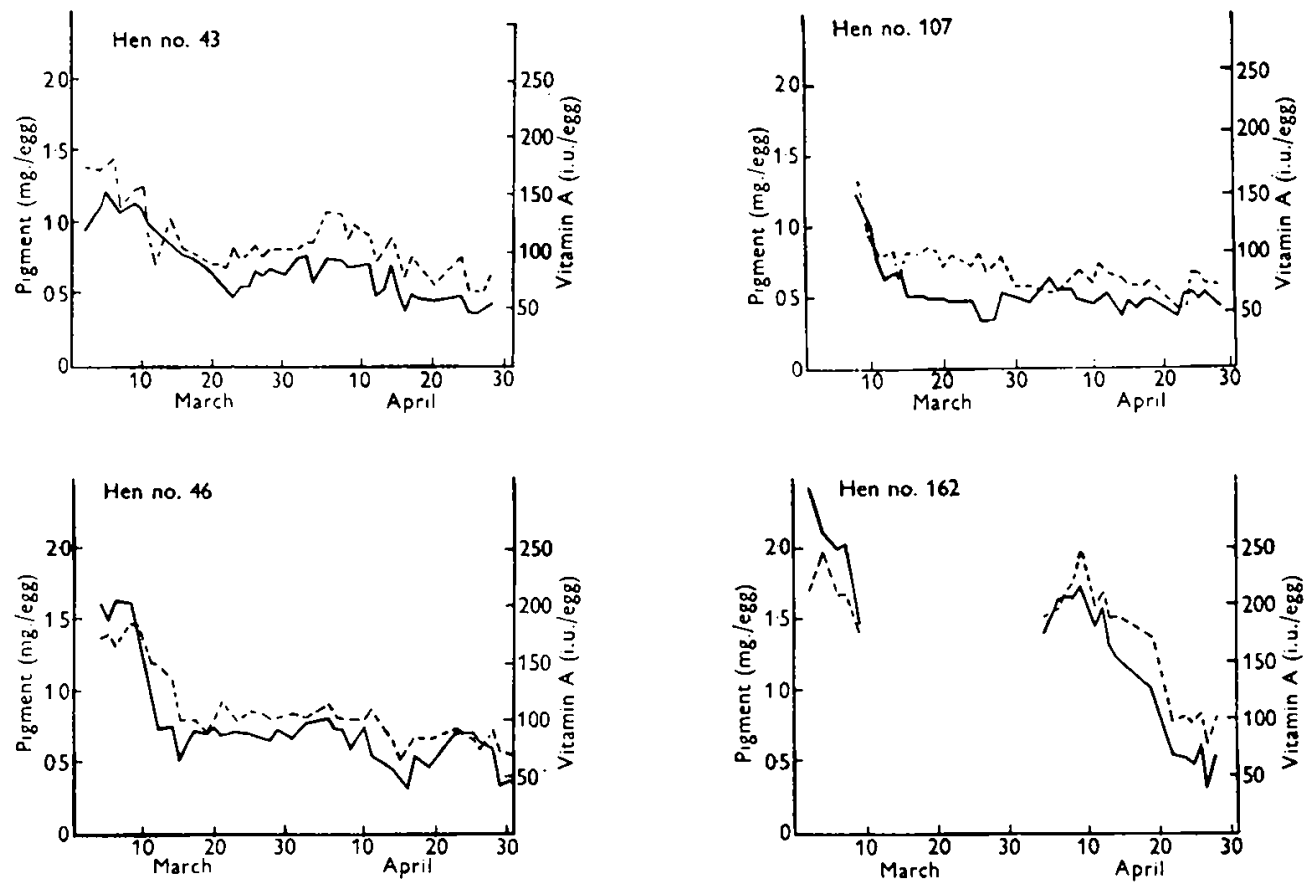

Fig. I. Pigment and vitamin A contents of individual eggs from four Rhode Island Red hens.

The regression lines of $X$ (pigment in mg./egg) upon $Y$ (vitamin $\mathrm{A}$ in i.u./egg) and of $Y$ upon $X$ are shown diagrammatically in Fig. 2, and the regression equations are summarized in Table 2.

\section{DISCUSSION}

From these results two principal points of significance emerge. The first is that where the carotenoid pigments of grass are the only source of vitamin A available to the hen, the pigment and vitamin A contents of the eggs run closely parallel to one another. The second is that during a period of rest from production the hen accumulates, if conditions permit, considerable quantities of carotenoid pigment and vitamin $\mathrm{A}$ and releases them 
rapidly into the first few eggs laid at the beginning of the laying period. The first eggs laid at the beginning of lay therefore differ appreciably in composition from those laid later in the period.
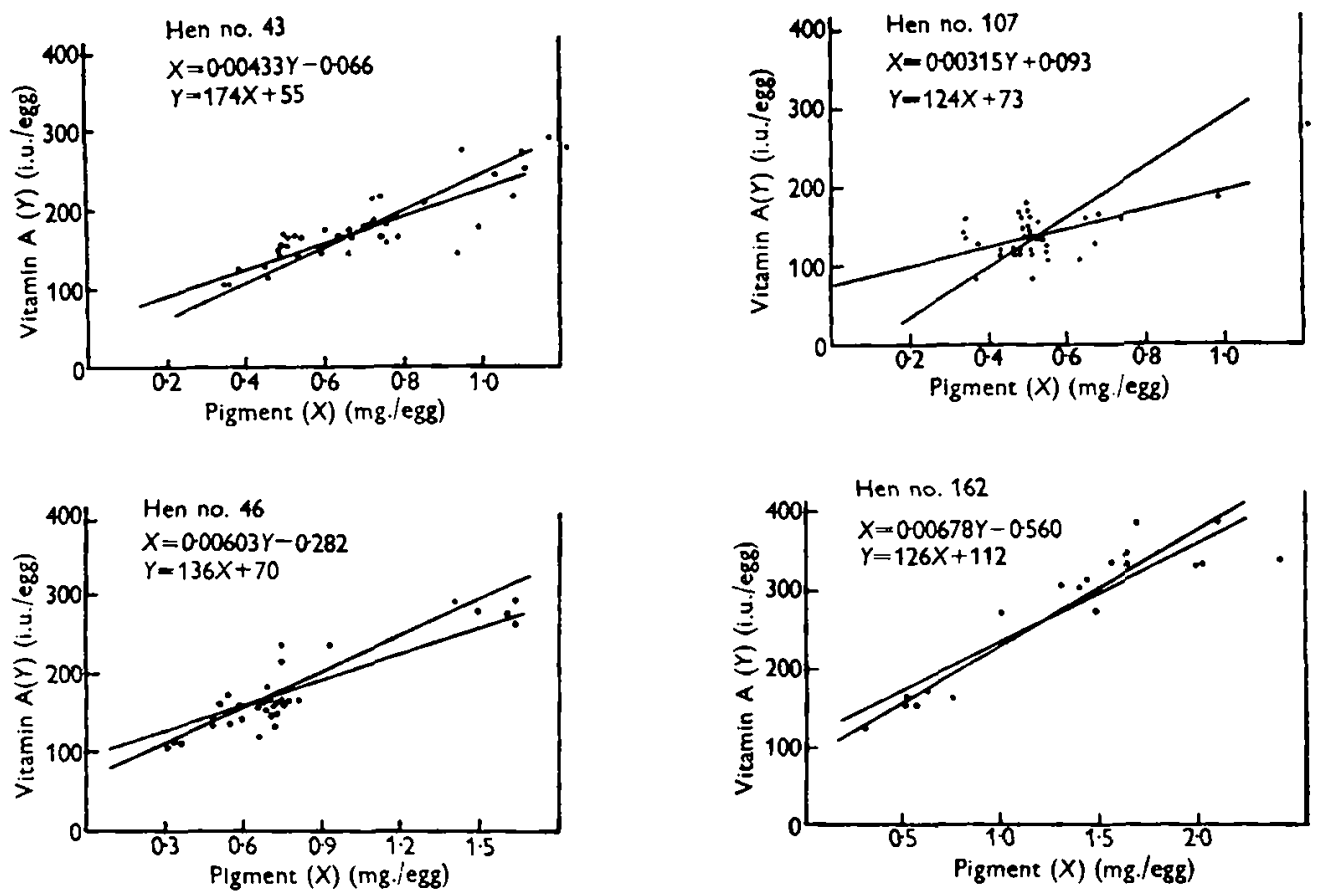

Fig. 2. Relationship between the pigment and vitamin $A$ in eggs from four Rhode Island Red hens.

The relationship between the pigment and ritamin $A$ contents of eggs

As in this experiment the carotenoid pigments of grass were the sole source of vitamin $A$ available to the hens, some correlation between the pigment content of eggs and their vitamin A content might have been expected. The results listed in Table 2 indicate that the relationship is a very close one, sufficiently close in fact to allow the pigment content of any egg yolk to be useful in calculating its vitamin A content. From the regression equations it is seen that $\mathrm{I} \mathrm{mg}$. pigment was accompanied by 229, 197 , 206 and 238 i.u. vitamin $A$ in the eggs of hens nos. 43, 107, 46 and 162 respectively; these values are of the same order of magnitude.

\section{The accumulation and release of pigment and vitamin $A$}

The accumulation and release of both pigment and vitamin $A$ is probably of considerable significance from the breeder's point of view in that the hatchability of the eggs and the vitality of the chicks produced from them, early in the laying period, may be affected. In this experiment the hens came into production in late winter after resting from egg production for varying lengths of time. Their only sources of pigment and vitamin A were the carotenoid pigments of grass, to which the birds had free access. 
The amount of pigment and vitamin $A$ accumulated during the periods of rest from production must depend primarily on the following factors:

(1) The length of the period of rest from production.

(2) The condition of the herbage during this time and the relative amounts of vitamin $\mathrm{A}$-active and vitamin $\mathrm{A}$-inactive pigments eaten by the hen.

(3) The efficiency and speed of conversion of vitamin A-active pigments to vitamin A by the individual hens.

Effect of the length of the period of rest from production. The high concentrations of pigment and vitamin $A$ in the first eggs laid indicate that some of the accumulated reserves are quickly released at the beginning of lay and it is reasonable to suppose that the longer the period of rest from production before laying, the greater the accumulation of reserves and the greater the concentrations of pigment and vitamin $A$ in the first eggs laid. The number of birds in this experiment was too small to supply conclusive data to prove this point, but further data were available from another investigation where the first eggs from eight birds, which had rested for varying lengths of time during the late winter and had started to lay at about the same time in early spring, had been examined for pigment and vitamin A. The results are recorded in Tables 3 and 4 ,

Table 3. Influence of the length of the rest period of Rhode Island Red hens on the pigment and vitamin $A$ contents of the first egg laid after it

$\begin{array}{cccc}\text { Hen no. } & \begin{array}{c}\text { Length of } \\ \text { rest period } \\ \text { (days) }\end{array} & \begin{array}{c}\text { Pigment content } \\ \text { of yolk } \\ \text { (mg.) }\end{array} & \begin{array}{c}\text { Vitamin A content } \\ \text { of yolk } \\ \text { (i.u.) }\end{array} \\ 66 \text { I } & \text { II } & 1 \cdot 12 & 284 \\ 786 & \text { I1 } & 2 \cdot 02 & 316 \\ 165 & \text { I2 } & 3 \cdot 54 & 452 \\ 898 & \text { 16 } & 1 \cdot 93 & 336 \\ 250 & 17 & 2 \cdot 02 & 380 \\ 121 & 21 & 2 \cdot 36 & 380 \\ \text { 171 } & 22 & 2 \cdot 94 & 420 \\ 655 & 32 & 1 \cdot 66 & 550\end{array}$

Table 4. Relation between the lengths of the rest periods of eight Rhode Island Red hens and the pigment and vitamin $A$ contents of the first eggs laid subsequently

\begin{tabular}{lccl} 
No. of & $\begin{array}{c}\text { Correlation } \\
\text { determinations }\end{array}$ & coefficient & \multicolumn{1}{c}{ Significance } \\
Length of rest period and pigment & 8 & -0.069 & Not significant \\
Length of rest period and vitamin A & 8 & 0.785 & Significant
\end{tabular}

The influence of the length of the period of rest from production in days $(X)$ on the vitamin $A$ content $(Y)$ of the first egg laid after it is expressed quantitatively by the following regression equation:

$$
Y=9 \cdot 27 X+225
$$

and shown diagrammatically in Fig. 3; they indicate that there is in fact a significant correlation between the vitamin A content of the first egg, laid after a period of rest from production, and the length of the rest period. From the regression equation it is seen that on the average 9.3 i.u. stored vitamin A were transferred to the first eggs for each day that the hens rested from production, this daily increase supplementing a constant minimal level of 225 i.u. vitamin A. 
No similar relationship was observed for the pigment content of the first eggs laid and the length of the rest period. 'The absence of correlation is probably due to the absence of any precise mechanism for the storage and release of pigment such as there is for vitamin A. The principal site of accumulation of vitamin $A$ is the liver, this organ apparently possessing a peculiar affinity for vitamin $A$ and the ability to control its utilization. 'The liver does not show the same tendency to accumulate pigment, and, although some carotenoid pigment is invariably found in liver fat, the amount is com-

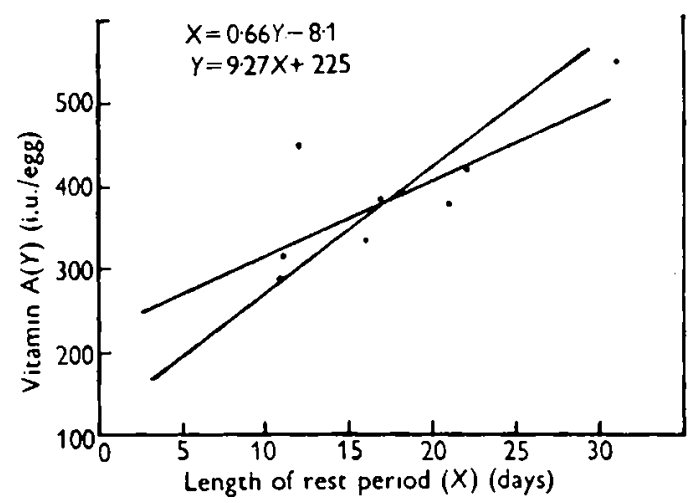

Fig. 3. Relationship between the length of the rest period of Rhode Island Red hens and the vitamin A content of the first egg laid after it.

paratively small. Fat-soluble pigments absorbed by the hen find their way into the various internal fat depots, including the liver and subcutaneous fat, and visible accumulations occur in the skin covering the shanks, in the beak, and in the iris of the eye. Obviously then different mechanisms are involved for the mobilization and transport of stored pigment and stored vitamin A. Once pigment and vitamin A reach their respective storage depots, the rates at which they become available for transference to egg yolk need not necessarily be the same and may be expected to be appreciably different. Where the pigment and vitamin $A$ are derived not from stored depots but from the vitamin $A$-active and the inactive pigments recently ingested by the laying hen, a closer relationship between them can be expected. This relationship is discussed fully on p. $33^{\circ}$.

Effect of the condition of the herbage. The condition of the herbage available to the fowls, particularly from the point of view of its $\beta$-carotene content, must necessarily be of importance, but it is probably of less significance than might at first be supposed. The $\beta$-carotene content of grass is at a maximum when the grass is in the stage of vigorous growth, i.e. during early spring and early autumn. The $\beta$-carotene content of grass falls when the grass matures and ripens in summer, and when the critical temperature for assimilation is approached in winter. But, although such variations in the $\beta$-carotene content of grass occur, it should be pointed out that the fowl is a selective feeder and can exert a fine choice of the food it consumes. It is reasonable to suppose that the fowl will show a preference for the young grass shoots with a relatively high content of $\beta$-carotene, and for this reason the grass feed of the fowl is probably 
much more constant in composition than the variations in the $\beta$-carotene content of the grass as a whole would suggest. The fowl is probably consuming young grass rich in $\beta$-carotene for the greater part of the year, the consumption being least in the height of summer, particularly if drought conditions persist at this time.

Effect of the conversion of $\beta$-carotene to vitamin $A$. The close relationship between the pigment and vitamin $\mathrm{A}$ contents of individual eggs indicates that the inactive carotenoids and the vitamin A converted from simultaneously ingested $\beta$-carotene are made available for transference to the same yolk, and this further indicates that the hen is able to convert $\beta$-carotene rapidly to vitamin $\mathrm{A}$.

'The results also throw some light on the efficiency with which the individual birds make this conversion. If the pigment content of any egg is accepted as a measure of the $\beta$-carotene simultaneously ingested, the amount of vitamin A associated with the pigment content of the eggs of each bird gives an indication of the relative efficiency with which it makes the conversion. The regression coefficients listed in 'l'able 2 have been compared by the $t$ test ('Student', 1908, 1925) and the results of this comparison are given in Table 5. They show that hens nos. 46 and 162 made the conversion with

'Table 5. Comparison of the individual efficiencies of conversion of $\beta$-carotene into vitamin $A$ by four Rhode Island Red hens

\begin{tabular}{|c|c|c|c|c|c|}
\hline $\begin{array}{l}\text { Hen } \\
\text { nos. }\end{array}$ & $\begin{array}{l}\text { Coefficients } \\
\text { of } X^{*}\end{array}$ & $t$ & $\begin{array}{c}\text { Degrees of } \\
\text { freedom }\end{array}$ & $P$ & Significance \\
\hline $\begin{array}{r}43 \\
107\end{array}$ & $\left.\begin{array}{l}174 \\
124\end{array}\right\}$ & $\mathrm{I} \cdot 68$ & 77 & 0.09 & No significant difference \\
\hline $\begin{array}{l}43 \\
46\end{array}$ & $\left.\begin{array}{l}174 \\
136\end{array}\right\}$ & 2.00 & 76 & 0.04 & Significantly different \\
\hline $\begin{array}{r}43 \\
162\end{array}$ & $\left.\begin{array}{l}174 \\
126\end{array}\right\}$ & 2.50 & 59 & 0.01 & Significantly different \\
\hline $\begin{array}{r}107 \\
46\end{array}$ & $\left.\begin{array}{l}x \geq 4 \\
136\end{array}\right\}$ & 0.44 & 73 & 0.70 & No significant difference \\
\hline $\begin{array}{l}107 \\
162\end{array}$ & $\left.\begin{array}{l}124\} \\
126\end{array}\right\}$ & 0.07 & $5^{6}$ & 0.90 & No significant difference \\
\hline $\begin{array}{r}46 \\
162\end{array}$ & $\begin{array}{l}136) \\
126 f\end{array}$ & 0.62 & 55 & 0.55 & No significant difference \\
\hline
\end{tabular}

approximately equal efficiency, but with a lower efficiency than hen no. 43. The performance of hen no. 107 is in some doubt owing to the considerably greater spread of the results for this bird.

Without a knowledge of the carotenoid content of the herbage and its composition, it is not possible to determine the absolute efficiency with which the hens converted $\beta$-carotene to vitamin $A$, and unfortunately this information was not obtained.

\section{SUMMARY}

I. An examination was made of the eggs from four birds from a breeding flock of Rhode Island Red hens maintained on a grain ration free from pigment and vitamin $\mathrm{A}$ but allowed free access to good pasture.

2. 'Total carotenoid pigments and vitamin A were determined on successive eggs 
from the first egg laid in spring through an 8-week period of the following laying period.

3. The results indicate that vitamin $\mathrm{A}$ and carotenoid pigment, stored during the period before laying, are transferred in high concentrations to the first few eggs laid, and that the concentrations fall quickly as the laying period progresses.

4. The significance of these changes is discussed.

\section{REFERENCES}

Capper, N. S., McKibbin, I. M. W. \& Prentice, J. H. (193x). Biochem. F. 25, 265.

Cruickshank, E. M. (1940). F. Soc. chem. Ind., Lond., 59, 415.

Gillam, A. E. \& Heilbron, I. M. (1935). Biochem. F. 29, 1064.

Kline, O. L., Schultze, M. O. \& Hart, E. B. (1932). F. biol. Chem. 97, 83 .

Kon, S. K. (1940). F. Soc. chem. Ind., Lond., 59, 360.

Kuhn, R., Winterstein, A. \& Lederer, E. (1931). Hoppe-Seyl. Z. 197, 141.

Moore, T. (1930). Biochem. F. 24, 692.

Palmer, L. S. \& Kempster, H. L. (1919). Y. biol. Chem. 39, 299.

Palmer, L. S. \& Kennedy, C. (192I). F. biol. Chem. 46, 559.

Plimmer, R. H. A., Rosedale, J. L. \& Raymond, W. H. (1923). Biochem. F. 17, 787.

Rydbom, M. (1933). Biochem. Z. 258, 239.

Schunck, C. A. (1903). Proc. roy. Soc. 72, 165.

'Student' (1908). Biometrika, 6, r.

'Student' (1925). Metron, 5, 105.

Thudichum, J. L. W. (1869). Proc. roy. Soc. 17, 253.

Virgin, E. \& Klussmann, E. (1932). Hoppe-Seyl. Z. 213, I6.

von Euler, H. \& Klussmann, E. (1932). Hoppe-Seyl. Z. 208, 50.

Willstatter, R. \& Escher, H. H. (IgII). Hoppe-Seyl. Z. 78, 214. 